\title{
Use of Terahertz-Raman Spectroscopy to Determine Solubility of the Crystalline Active Pharmaceutical Ingredient in Polymeric Matrices during Hot Melt Extrusion
}

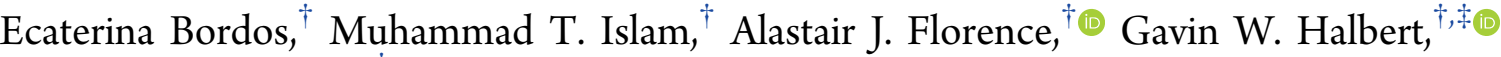 \\ and John Robertson* ${ }^{\dagger}$ (1)
}

${ }^{\dagger}$ EPSRC Future Manufacturing Research Hub, CMAC, University of Strathclyde, Technology and Innovation Centre, 99 George Street, Glasgow G1 1RD, U.K.

${ }^{\ddagger}$ Cancer Research UK Formulation Unit, SIPBS, University of Strathclyde, 161 Cathedral Street, Glasgow G4 0RE, U.K.

Supporting Information

ABSTRACT: Polymer-based amorphous solid dispersions (ASDs) comprise one of the most promising formulation strategies devised to improve the oral bioavailability of poorly water-soluble drugs. Exploitation of such systems in marketed products has been limited because of poor understanding of physical stability. The internal disordered structure and increased free energy provide a thermodynamic driving force for phase separation and recrystallization, which can compromise therapeutic efficacy and limit product shelf life. A primary concern in the development of stable ASDs is the solubility of the drug in the polymeric carrier, but there is a scarcity of reliable analytical techniques for its determination.

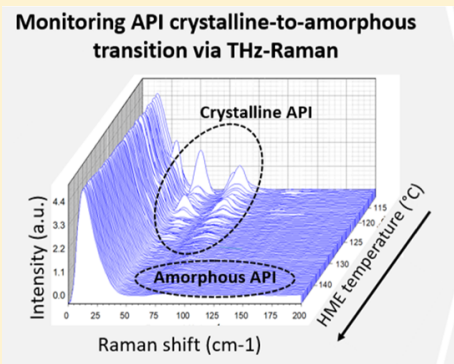

Understanding fundamental ASD stability
Real-time API-polymer solubility determination

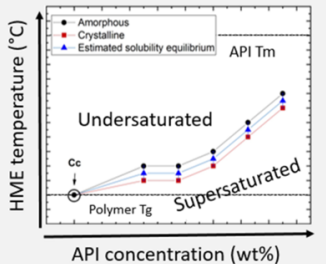

API concentration (wt\%) In this work, terahertz $(\mathrm{THz})$ Raman spectroscopy was introduced as a novel empirical approach to determine the saturated solubility of crystalline active pharmaceutical ingredient (API) in polymeric matrices directly during hot melt extrusion. The solubility of a model compound, paracetamol, in two polymer systems, Affinisol 15LV (HPMC) and Plasdone S630 (copovidone), was determined by monitoring the API structural phase transitions from crystalline to amorphous as an excess of crystalline drug dissolved in the polymeric matrix. THz-Raman results enabled construction of solubility phase diagrams and highlighted significant differences in the solubilization capacity of the two polymer systems. The maximum stable API-load was $20 \mathrm{wt} \%$ for Affinisol 15LV and $40 \mathrm{wt} \%$ for Plasdone S630. Differential scanning calorimetry and XRPD studies corroborated these results. This approach has demonstrated a novel capability to provide real-time API-polymer phase equilibria data in a manufacturing relevant environment and promising potential to predict solid-state solubility and physical stability of ASDs.

KEYWORDS: amorphous solid dispersion, API-polymer solubility, Terahertz-Raman spectroscopy, stability prediction

\section{INTRODUCTION}

Poor aqueous solubility is a major concern in the pharmaceutical field that can compromise the amount of drug available for absorption, lead to low bioavailability, and detract from the drug's inherent therapeutic efficacy. ${ }^{1,2}$ It is expected that around $90 \%$ of the new chemical entities possess poor aqueous solubility and fall into class II or IV of the Biopharmaceutics Classification System (BCS), limiting their further development. ${ }^{3}$ Amorphous solid dispersions (ASDs) comprise one of the most promising formulation approaches developed to address this challenge. ASDs, where active pharmaceutical ingredients (APIs) are molecularly dispersed in amorphous polymeric carriers have been shown to achieve faster dissolution rates and higher apparent solubility. ${ }^{4-7}$ Such systems provide solubility enhancement primarily via API amorphization; however, increased porosity and improved wettability have also been reported as enabling factors. ${ }^{8}$ In the amorphous state, the API is in its highest energy state and as a result, no energy is required to break the crystal lattice and amorphous materials generally have better aqueous solubility than their crystalline counterparts. ${ }^{9,10}$ However, the internal disordered structure and increased free energy provide a thermodynamic driving force for phase separation and recrystallization, which makes the design of stable ASDs highly challenging.

Despite decades of pharmaceutical research since the first solid dispersion was developed in 1961 by Sekiguchi and Obi, ${ }^{11}$ ASDs are still not fully exploited in marketed products. Because of poor physical stability and lack of proper understanding of the thermodynamic, kinetic, and molecular aspects involved in the stabilization of these systems, their

Received: June 26, 2019

Revised: August 14, 2019

Accepted: August 22, 2019

Published: August 22, 2019 
development is still largely by trial and error, being both timeand resource-consuming. ${ }^{12,13}$ The solubility of the API in the carrier polymer is one of the key factors determining physical stability and API recrystallization propensity. ${ }^{14-16}$ Its determination is of paramount importance in the manufacture of crystal-free, stable ASDs and is therefore of considerable commercial importance with regard to shelf life of this class of pharmaceutical products. If the API concentration in the formulation is below the equilibrium solubility, the ASD will be thermodynamically stable and will not recrystallize in the absence of additional stress factors. When the API content exceeds its thermodynamic solubility, the ASD becomes supersaturated and API phase separation and recrystallization are likely to occur. ${ }^{17}$ However, if the system is kinetically stabilized at storage conditions, molecular mobility may be slowed enough to retain the amorphous configuration and inhibit recrystallization during pharmaceutically relevant time periods. $^{18}$

Solubility determination of a drug in a polymer matrix is an analytically challenging task as both components are normally solid at room temperature and because of high viscosity of the polymeric carrier, equilibrium solubility is difficult to reach and test. $^{19,20}$ In fact, the current pack of "industry standard" analytical techniques is limited in that it is often based on differential scanning calorimetry (DSC) analysis or inferred based on postproduction analysis, providing an account of the material state after manufacturing is complete. The DSC methods include the melting point depression method, the recrystallization method, and the enthalpy approach amongst others. ${ }^{14,19,21,22}$ Aside from thermal degradation and chemical instability, these methods generally risk solubility underestimation because of low molecular mobility in a viscous polymer (i.e., no mixing is applied) and require equilibrium assumptions which limits their wider applications.

Because access to experimental solubility data is only possible at high temperature, a number of thermodynamicbased models have been adjusted to predict solubility at storage conditions. A commonly employed model for this purpose is based on the Flory-Huggins (FH) lattice theory. Although it was never intended for systems in which hydrogen bonding interactions are important, as is the case for most ASDs, it has been effectively applied to several polymeric systems. ${ }^{23,24}$ Nonetheless, examples of inaccurate predictions using this approach have also been reported. ${ }^{20,25}$ Alternative methods include the empirical model by Kyeremateng et al., ${ }^{26}$ and more recently, the Perturbed-Chain Statistical Associating Fluid Theory (PC-SAFT) developed by Gross and Sadowski. ${ }^{27-29}$

There is a growing body of evidence suggesting that the apparent solubility of an API in the polymer system may vary according to the processing method used. ${ }^{30-32}$ This may be driven by differences in mixing rather than true thermodynamic equilibrium being reached. Within this work, a corotating twin screw extruder was used as the mixing device. This type of unit provides intense mixing and has the potential to overcome kinetic limitations and reach true equilibrium. Therefore, the objective of this study was to determine API solubility directly during hot melt extrusion (HME) processing. This was achieved by monitoring the API crystalline to amorphous structural phase transitions taking place in the lowfrequency terahertz-Raman region as it dissolves in the polymer. For this purpose, paracetamol (whilst not presenting in vivo solubility constraints) was selected as the model compound and two commercially relevant polymer systems, Affinisol 15LV (hydroxypropyl methylcellulose) and Plasdone S630 (copovidone) as polymeric carriers, to assess the above application of THz-Raman. Extrusion was performed at different API-polymer ratios and for each composition, different processing temperatures were explored to allow phase-equilibria inferences and construction of temperaturecomposition phase diagrams.

\section{MATERIALS AND METHODS}

Materials. Pharmaceutical grade granular paracetamol (PCM) was purchased from Mallinckrodt Inc. (Raleigh, USA). Hydroxypropyl methylcellulose grade Affinisol $15 \mathrm{LV}$ (AFF) and copovidone (PVP/VA 6:4) grade Plasdone S630 (PLSD) were kindly donated by Dow Inc. (The Dow Chemical Company, Michigan, USA) and Ashland Inc. (Columbus, OH, USA), respectively. The chemical structure of all materials is displayed in Figure 1. All compounds were used as obtained, without further purification.

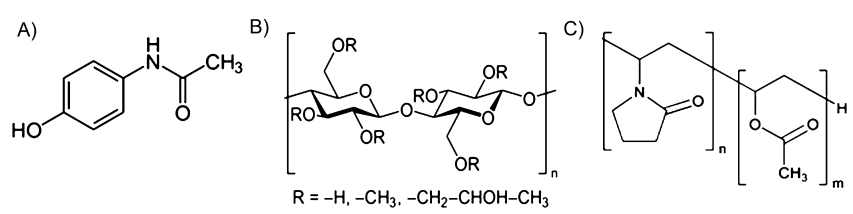

Figure 1. Chemical structure of (A) Paracetamol, (B) Affinisol 15LV and (C) Plasdone S630. " $n$ " and " $m$ " represent the structural unit for both polymers. Plasdone $S 630$ is a linear copolymer where $n / m=6 / 4$ mass ratio.

Methods. Preparation of ASDs by HME. HME was performed with a Eurolab 16 Twin-screw extruder (Thermo Scientific, Karlsruhe, Germany) equipped with two DDW-M FW20 feeders (Brabender Technologie, Duisburg, Germany) operating in the gravimetric mode with a vertical crammer hopper (Brabender Technologie, Duisburg, Germany) set to $100 \mathrm{rpm}$. The experimental set-up was as illustrated in Figure 2. API and polymers were separately fed at different feeding rates to reach the desired API-polymer ratio. A combined feeding rate of $1 \mathrm{~kg} / \mathrm{h}$ was used. For all experiments, barrel zone 1 was operated at $20{ }^{\circ} \mathrm{C}$ and barrel zones 2 and 3 were controlled at temperature set points of 50 and $100{ }^{\circ} \mathrm{C}$, respectively, to prevent powder melting and blockage of the feeding zone. The processing temperature limits of the remaining barrel zones were constrained by the polymer glass transition temperature (Affinisol $15 \mathrm{LV}-115{ }^{\circ} \mathrm{C}$ and Plasdone S630-109 $\left.{ }^{\circ} \mathrm{C}\right)$ and the drug melting point (170 ${ }^{\circ} \mathrm{C}$ ). This was required to assure the soften/liquefied state of the polymer (i.e., act as a "liquid solvent") to mix and dissolve the API, while keeping the API below its melting point to enable detection of the excess crystalline API. Barrel sections 4-10 and die zone were controlled to the same temperature set point values, which are reported in Tables 1 and 2 . Product melt temperature was monitored with a pressure-temperature probe (Terwin Instruments Ltd., Bottesford, UK) immersed in the polymer-API mixture within the confines of the die section. The temperature values measured in barrel sections $4-10$, the die and the product melt probe varied from reported set point values less than $\pm 3{ }^{\circ} \mathrm{C}$. Therefore, within the present work, we quote temperature values as the set-point temperature values. Collected extrudates were pelletized and stored at $25{ }^{\circ} \mathrm{C} / 60 \% \mathrm{RH}$ until further analysis. 


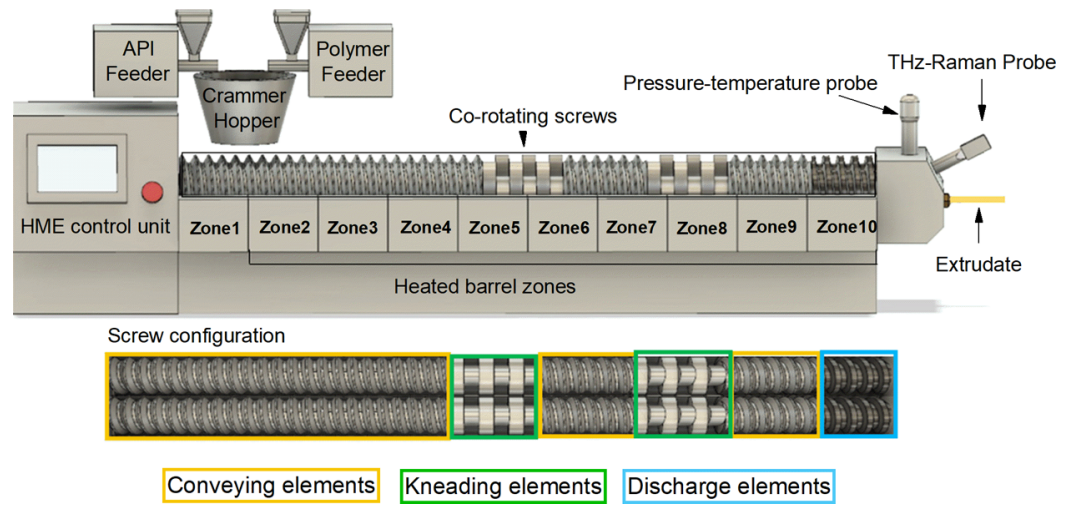

Figure 2. Schematic representation of the experimental HME set-up and screw configuration.

Table 1. Hot Melt Extrusion Experimental Conditions for PCM-AFF System

\begin{tabular}{|c|c|c|c|}
\hline $\begin{array}{l}\text { API } \\
\text { feeding } \\
\text { rate } \\
(\mathrm{kg} / \mathrm{h})\end{array}$ & $\begin{array}{l}\text { polymer } \\
\text { feeding rate } \\
(\mathrm{kg} / \mathrm{h})\end{array}$ & $\begin{array}{l}\text { processing temperature }\left({ }^{\circ} \mathrm{C}\right) \\
\text { (Barrel sections } 4-10 \text { and die zone })^{a}\end{array}$ & $\begin{array}{l}\text { screw } \\
\text { speed } \\
(\mathrm{rpm})\end{array}$ \\
\hline 0.1 & 0.9 & $115,130,150,170$ & 200 \\
\hline 0.2 & 0.8 & $115,120,125,130,140,150$ & 200 \\
\hline 0.25 & 0.75 & $115,120,125,130,140,150,160,170$ & 200 \\
\hline 0.275 & 0.725 & $115,120,125,130,140,150$ & 200 \\
\hline 0.3 & 0.7 & $115,120,125,130,140$ & 200 \\
\hline 0.325 & 0.675 & $115,120,125,130,135,140$ & 200 \\
\hline 0.35 & 0.65 & $115,120,125,130,135,140,145,150$ & 200 \\
\hline
\end{tabular}

${ }^{a}$ Each value in this column represents a distinct experimental condition and denotes the cumulative set-point barrel temperature of sections 4-10 and die (i.e. zones 4-10 and the die were operated isothermally).

Table 2. Hot Melt Extrusion Experimental Conditions for PCM-PLSD System

\begin{tabular}{llll}
$\begin{array}{c}\text { API } \\
\text { feeding } \\
\text { rate } \\
(\mathrm{kg} / \mathrm{h})\end{array}$ & $\begin{array}{c}\text { polymer } \\
\text { feeding rate } \\
(\mathrm{kg} / \mathrm{h})\end{array}$ & $\begin{array}{c}\text { processing temperature }\left({ }^{\circ} \mathrm{C}\right) \\
(\text { Barrel sections 4-10 and die zone })^{a}\end{array}$ & $\begin{array}{c}\text { screw } \\
\text { speed } \\
(\mathrm{rpm})\end{array}$ \\
0.3 & 0.7 & $110,120,130,150$ & 200 \\
0.35 & 0.65 & 110 & 200 \\
0.375 & 0.625 & 110,120 & 200 \\
0.4 & 0.6 & $110,120,130$ & 200 \\
0.425 & 0.575 & $110,120,130,140$ & 200 \\
0.45 & 0.55 & $110,120,130,140,150$ & 200 \\
0.475 & 0.525 & $110,120,130,140,150$ & 200 \\
0.50 & 0.5 & $110,120,140,150$ & 200 \\
0.525 & 0.475 & 150 & 200 \\
0.55 & 0.45 & 150 & 200 \\
0.575 & 0.425 & 150 & 200 \\
0.6 & 0.4 & 150,160 & 200 \\
0.625 & 0.375 & 150,160 & 200 \\
0.65 & 0.35 & $150,160,170$ & 200 \\
0.675 & 0.325 & $150,160,170$ & 200 \\
0.70 & 0.3 & $150,160,170$ & \\
\hline
\end{tabular}

${ }^{a}$ Each value in this column represents a distinct experimental condition and denotes the cumulative set-point barrel temperature of sections 4-10 and die (i.e. zones 4-10 and the die were operated isothermally).

Terahertz-Raman API-Polymer Solubility Measurements. A terahertz-Raman probe (Ondax Inc., USA) coupled with a RNX1 Raman spectrometer unit (Kaiser Optical Systems Inc.,
USA) was immersed in the polymer API-mixture in an adjacent port immediately beside the pressure temperature probe to monitor the API structural phase transitions occurring during extrusion. Data were collected with a $785 \mathrm{~nm}$ laser excitation source operating at $70 \mathrm{~mW}$ power. An exposure time of $2 \mathrm{~s}$ and three spectral accumulations were used. Spectra were acquired with Holograms software (version 4.1) over the -20 to $1800 \mathrm{~cm}^{-1}$ spectral range and integrated into PharmaMV RealTime software (version 5.2, Perceptive Engineering Ltd., Daresbury, UK) for real-time visualization. Spectral preprocessing was performed with PharmaMV Development software (version 5.2) applying Whittaker smoothing and standard normal variate for baseline effect removal and normalization, respectively. Thermally induced transitions in the low-frequency terahertz-Raman region (5$\left.200 \mathrm{~cm}^{-1} / 0.15-6.0 \mathrm{THz}\right)$ were used to distinguish between the crystalline and amorphous states of the API. Transition temperatures from crystalline-to-amorphous and amorphousto-crystalline were used to determine the temperaturecomposition coordinates at each API-polymer ratio and construct the solubility phase diagram for both systems.

Off-Line Terahertz-Raman Spectroscopy. Off-line variabletemperature $\mathrm{THz}$-Raman analysis was performed to obtain the reference spectra of each PCM polymorph and amorphous paracetamol. Data were collected with the terahertz-Raman probe (coupled with a RNX1 spectrometer unit) attached to a Linkam LTS420 hot stage. To prepare the amorphous paracetamol and the three polymorphs, the temperature cycling method outlined by Nanubolu and Burley was adopted. ${ }^{33}$ PCM samples of 3-5 mg were confined between a microscope glass and a cover slip and heated to $180{ }^{\circ} \mathrm{C}$ at a rate of $20{ }^{\circ} \mathrm{C} / \mathrm{min}$ and held at that temperature for $2 \mathrm{~min}$. Subsequent melt quenching to $0{ }^{\circ} \mathrm{C}$ was performed at a cooling rate of $20^{\circ} \mathrm{C} / \mathrm{min}$ to obtain the amorphous glass form. To obtain the paracetamol polymorphs, the amorphous glass from these steps was then allowed to equilibrate at $0{ }^{\circ} \mathrm{C}$ for 5 min prior to a second heating cycle to $180{ }^{\circ} \mathrm{C}$ using a heating rate of $1{ }^{\circ} \mathrm{C} / \mathrm{min}$. As the temperature rises at this slow heating rate, the glass transforms to PCM form III, then form II, and then form I before melting at $\sim 170{ }^{\circ} \mathrm{C}$. Therefore the reference spectra for the amorphous and three polymorphs were gathered through this cycle. At the specific transition temperatures identified $\left(80{ }^{\circ} \mathrm{C}\right.$ for form III, $120{ }^{\circ} \mathrm{C}$ for form II and $150{ }^{\circ} \mathrm{C}$ for form I), the heating rate was paused and the spectra was acquired using an exposure time of $2 \mathrm{~s}$ and three spectral accumulations. 
Hot Stage Microscopy. Hot-stage microscopy (HSM) experiments were conducted using a Leica DM2700 transmission optical microscope (Leica Microsystems, Milton Keynes, UK) under a cross-polarized light. The apparatus was equipped with a Leica DF320 digital camera (Leica Microsystems, Milton Keynes, UK) and a Linkam LTS420 T95 temperature control stage. Samples of 3-5 mg were placed into the hot-stage chamber and heated to $180{ }^{\circ} \mathrm{C}$ at a heating rate of $1{ }^{\circ} \mathrm{C} / \mathrm{min}$. Pure polymers and API-polymer physical mixtures were subjected to isothermal steps of $3 \mathrm{~min}$ at every $10{ }^{\circ} \mathrm{C}$ above $100{ }^{\circ} \mathrm{C}$ to equilibrate. The cooling cycle to $0{ }^{\circ} \mathrm{C}$ was performed at a rate of $1{ }^{\circ} \mathrm{C} / \mathrm{min}$. Birefringence properties of crystalline materials were used to distinguish the crystalline API from amorphous API-polymer mixtures. Pure PCM samples were confined between a microscope glass and a cover slip and subjected to an additional heat cycle to assess recrystallization behavior from the amorphous glass.

Differential Scanning Calorimetry. All experiments were performed on a DSC 214 Polyma differential scanning calorimeter (Netzsch-Gerätebau $\mathrm{GmbH}$, Germany) under a helium environment (purge $1=40 \mathrm{~mL} / \mathrm{min}$, purge $2=60 \mathrm{~mL}$ / $\mathrm{min})$. Samples of $3-5 \mathrm{mg}$ were accurately weighed and crimped in $25 \mu \mathrm{L}$ aluminium pans with pierced lids and subjected to heat-cool-heat cycles. Heating cycles were performed to $180{ }^{\circ} \mathrm{C}$ at a heating rate of $20{ }^{\circ} \mathrm{C} / \mathrm{min}$. Cooling was performed from 180 to $0{ }^{\circ} \mathrm{C}$ at $20^{\circ} \mathrm{C} / \mathrm{min}$.

$X$-ray Powder Diffraction. Variable temperature powder diffraction data (VT-XRPD) were collected using a Bruker D8 ADVANCE II diffractometer (Bruker Ltd., Coventry, UK) equipped with $\theta / \theta$ geometry and primary monochromated radiation $(\mathrm{Cu}, \lambda=1.54056 \AA)$. Data were collected in the $2 \theta$ range of $4^{\circ}-35^{\circ}$ using a step size of $0.017^{\circ}$ and $1 \mathrm{~s} /$ step speed. Operating voltage and current were $40 \mathrm{kV}$ and $50 \mathrm{~mA}$, respectively. Pure PCM samples were placed into $0.7 \mathrm{~mm}$ borosilicate glass capillaries and subjected to heat-cool-heat cycles to 180,0 and $180{ }^{\circ} \mathrm{C}$, respectively. Heating and cooling rates of $6{ }^{\circ} \mathrm{C} / \mathrm{min}$ were employed because of instrumental limitations. Identification of the crystalline form was made by comparison to CCSD crystalline forms I, II, and III (HXACAN27, HXACAN31 and HXACAN29, respectively) using Mercury software (version 3.9).

HME extrudates were analyzed at ambient temperature and data were collected on a Bruker AXS D8 ADVANCE transmission diffractometer equipped with the $\theta / \theta$ geometry, primary monochromated radiation $(\mathrm{Cu} \mathrm{K} \alpha 1 \lambda=1.54056 \AA$ ), and an automated multiposition $x-y$ sample stage. Samples were mounted on a polyimide film (Kapton, $7.5 \mu \mathrm{m}$ thickness) and analysis was performed in the angular range of $4^{\circ}-35^{\circ} 2 \theta$ with a $0.017^{\circ} 2 \theta$ step size and $2 \mathrm{~s}$ per step count time.

\section{RESULTS AND DISCUSSION}

Saturated Solution Temperature $\left(T_{S}\right)$ Determination. The main premise required to construct an API-polymer solubility phase diagram is the determination of the temperature at which a given crystalline API content is soluble in the polymer matrix. Access to this temperature was directly obtained during HME by monitoring the API structural phase transitions from crystalline to amorphous as it dissolved in the polymeric carrier. These phase transitions were monitored in the low-frequency $\mathrm{THz}$-Raman spectral region that covers the Stokes signal $\left(5-200 \mathrm{~cm}^{-1}\right)$ and provides information about the crystal lattice vibration (phonon) modes. ${ }^{34,35}$ Such vibrations are sensitive to local order and disorder, enabling distinction between different crystal packing arrangements, including the amorphous and crystalline states. $^{36,37}$

THz-Raman spectra of PLSD, AFF, amorphous, and crystalline PCM are shown in Figure 3. Crystalline PCM has

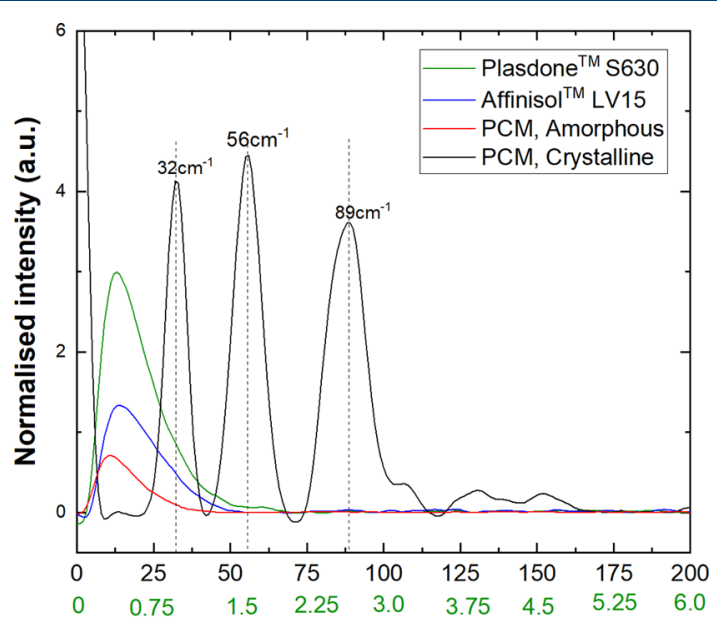

Raman shift $\left(\mathrm{cm}^{-1}\right)[\mathrm{THz}]$

Figure 3. Normalized THz-Raman spectra of PLSD (green), AFF (blue), amorphous PCM (red) and crystalline PCM (black).

distinctive peaks at 32,56 , and $89 \mathrm{~cm}^{-1}$ which are characteristic to form I. ${ }^{33}$ Given the lack of the long-range structural order in amorphous materials, these lattice modes are absent in the amorphous drug form and in both polymeric matrices and were used to differentiate between amorphous and crystalline PCM within the API-polymer mixtures. As the API dissolves in the polymer, the crystalline structure is disrupted and the drug is rendered amorphous. Therefore, to assure the robustness of the method, API solubility was determined by cycling extrusion temperature up, to induce dissolution and down, and to force drug precipitation.

As an example, Figure 4 illustrates the normalized spectra used to determine the saturated solution temperature $\left(T_{\mathrm{S}}\right)$ for PCM-AFF 30-70 wt \% (A-B) and PCM-PLSD 45-55 wt $\%(\mathrm{C}-\mathrm{D})$. As $T_{\text {EXTrusion }}$ approaches $T_{\mathrm{S}}$, the drug progressively dissolves in the polymer and the intensity of the lattice modes associated with crystalline PCM decreases until disappearing at $130{ }^{\circ} \mathrm{C}$ for PCM-AFF 30-70 wt \% (Figure 4B) and $150{ }^{\circ} \mathrm{C}$ for PCM-PLSD 45-55 wt \% (Figure $4 \mathrm{D})$, when the API content is fully amorphous. $\mathrm{T}_{S}$ was then estimated at the intermediate point between the API amorphous and crystalline phases, corresponding to $127.5^{\circ} \mathrm{C}$ for PCM-AFF $30-70$ wt $\%$ and $145^{\circ} \mathrm{C}$ for PCM-PLSD $45-$ 55 wt $\%$. It should be noted that to demonstrate the technique, $T_{\mathrm{S}}$ was approached by varying extrusion temperature using relatively large steps of $5{ }^{\circ} \mathrm{C}$ p/step for PCM-AFF and $10{ }^{\circ} \mathrm{C}$ $\mathrm{p} /$ step for PCM-PLSD. Therefore, solubility estimation is associated with an error of at least $\pm 2.5^{\circ} \mathrm{C}$ for PCM-AFF and $\pm 5{ }^{\circ} \mathrm{C}$ for PCM-PLSD.

Additionally, the product melt temperature may differ from set point temperature values as a result of heat from the shear between the screws and material, so care should be taken with regard to barrel zone temperature measurements and actual local material temperatures. ${ }^{38,39}$ Within this work, product melt temperature was monitored at the die section and typical \pm variation did not exceed $3{ }^{\circ} \mathrm{C}$ compared to the system set 

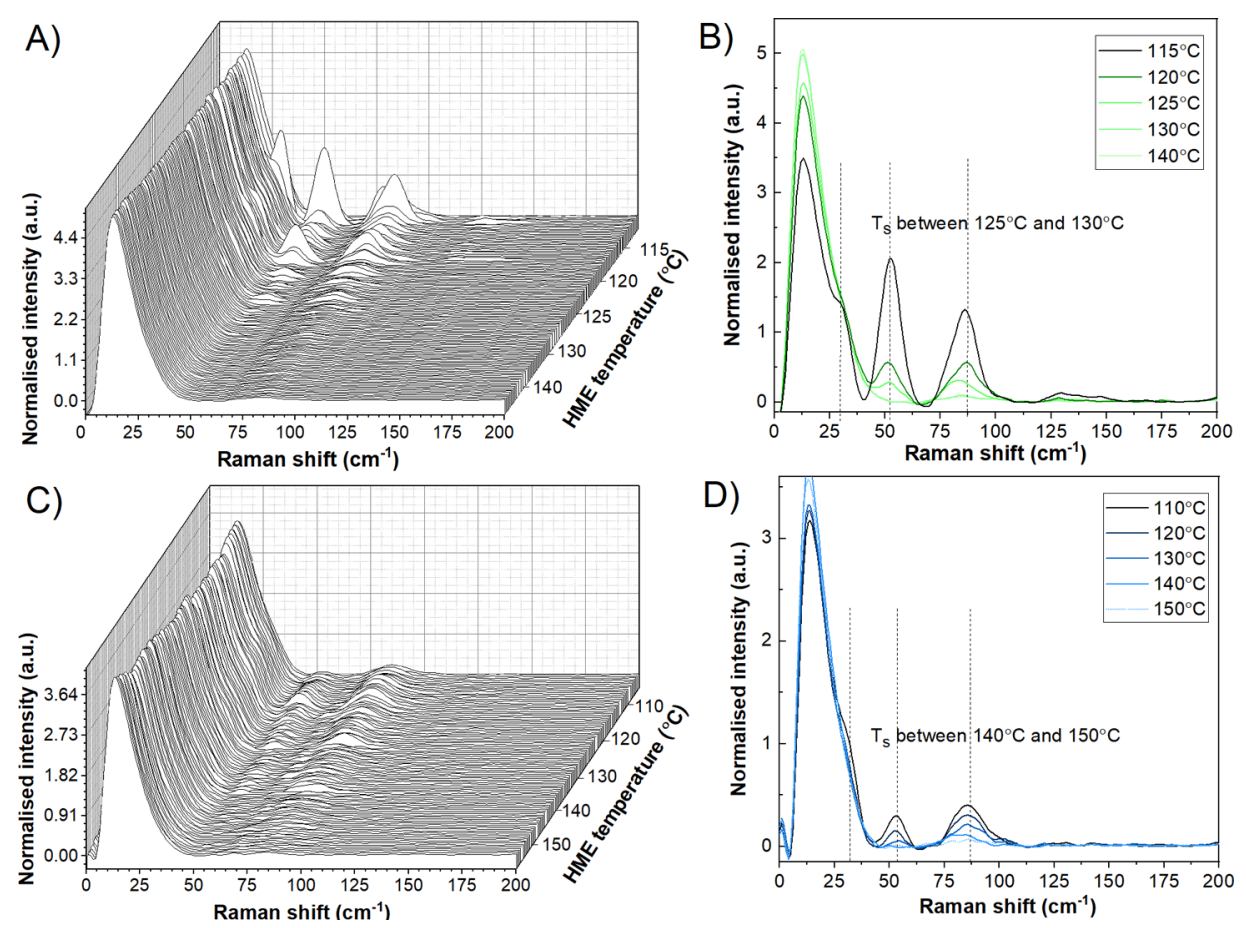

Figure 4. THz-Raman spectral evolution of (A,B) PCM-AFF 30-70 wt \% and (C,D) PCM-PLSD $45-55$ wt \% at different processing temperatures. In Figure (B,D) spectra are spatial averages of 20 spectra at each temperature.
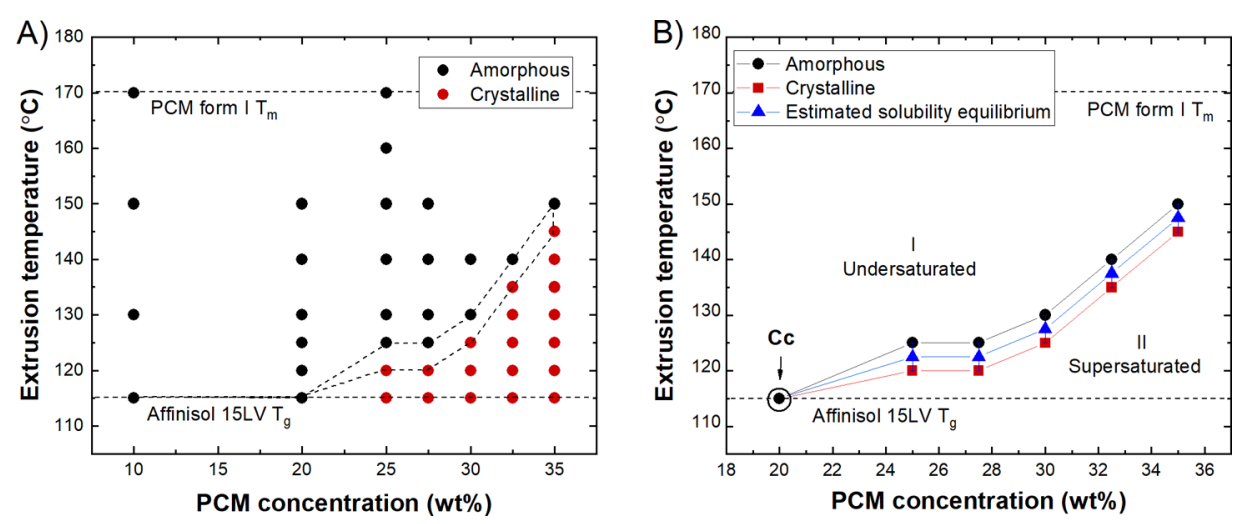

Figure 5. Phase behavior of PCM-AFF system during extrusion: (A) HME processing temperatures and API physical state; (B) estimated equilibrium solubility curve. Cc denotes the critical concentration up to which no crystallinity was found.
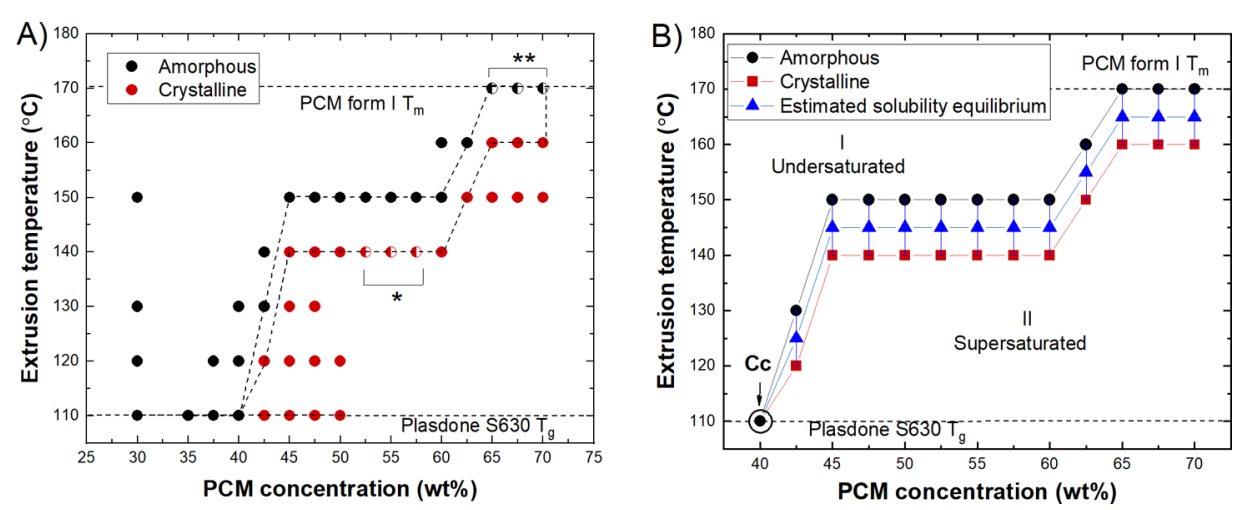

Figure 6. Phase behavior of PCM-PLSD system during extrusion: (A) HME processing temperatures and API physical state; (B) estimated equilibrium solubility curve. Cc denotes the critical concentration up to which no crystallinity was found; * denotes compositions expected to be crystalline at $140{ }^{\circ} \mathrm{C}$ based on crystallinity of adjacent compositions; ** denotes the composition range where the API amorphous character is not a direct reflection of the polymer solubilisation capacity due to the proximity to the API $T_{\mathrm{m}}$. 
point value. In the upstream sections, the extent of heating and cooling required to maintain set-point temperatures was examined. This showed that there was no substantial cooling requirement to compensate for frictional heat. Therefore, it was assumed that the reported temperature values are reflective of the local materials temperature within the system.

Using the same approach, $T_{\mathrm{S}}$ was determined for all APIpolymer compositions. For both systems, temperaturecomposition phase diagrams were generated by plotting the lowest temperature required for complete API amorphization (API dissolution end temperature) and the highest temperature at which residual crystalline API could be detected. Figures 5 and 6 show the amorphous and crystalline coordinates and the estimated equilibrium solubility curve as a function of the HME processing temperature for both systems.

Temperature-Composition Phase Diagrams. The drug phase-transition region demarks the boundary between the undersaturated region (region $\mathrm{I}$ in Figures $5 \mathrm{~B}$ and $6 \mathrm{~B}$ ) where the API is fully amorphous and the supersaturated region (region II in Figures 5B and 6B), where crystalline API particulates are suspended in a supersaturated API-polymer matrix. At certain API-polymer ratios, API dissolution showed no temperature dependence and complete miscibility was observed at all processing temperatures, including the polymer glass transition temperature $\left(T_{\mathrm{g}}\right)$. This was considered as the critical concentration $(\mathrm{Cc})$ as it defined the maximum API concentration where no crystallinity was found. The experimental limiting factor determining the lowest HME processing temperature for each system was the polymer $T_{g}$, to avoid solidification of the polymer and hence equipment blockage. Figure S1 shows the THz-Raman spectra at the critical concentration for both systems.

Paracetamol-Affinisol 15LV System. For Affinisol-based compositions, the API critical concentration was $20 \mathrm{wt} \%$ (Figure 5). Upon further increase of the API mass fraction, equilibrium solubility is reached at higher temperatures and an almost linear temperature increment is observed for mixtures $\geq 27.5$ wt $\%$ API-load. This observed trend is most likely to be a result of the relatively large temperature steps taken at the given compositions $\left(5^{\circ} \mathrm{C}\right.$ per step). Reducing the temperature steps could improve the accuracy in determining the position of the equilibrium temperature and refine the shape of the curve.

For all experimental compositions, the API dissolved at temperatures well below its melting point (e.g., $55^{\circ} \mathrm{C}$ lower at 20 wt \% API-load). This is indicative of good miscibility between the components and suggests a marked reduction of the drug's chemical potential in the presence of the polymer. ${ }^{40}$ The reduction in the chemical potential is usually observed using DSC through detection of a depressed melting point. ${ }^{22,41}$ However, these results show that spectroscopic methods can also be used to indirectly assess these phenomena. Moreover, this is a direct observation that extrusion can be performed at temperatures below the API melting point and attain complete drug solubilization. The correlation between the HME processing temperature, drug composition, and residual crystallinity has been pointed out to be of utmost importance to define HME processing boundaries and identify the optimal processing window to promote formation of molecular dispersions whilst avoiding drug/ polymer degradation. ${ }^{42,43}$ This is particularly relevant for ASDs containing thermally labile drug substances.
Paracetamol-Plasdone S630 System. Compared to Affinisol, Plasdone exhibited higher solubilization capacity and the API critical concentration up to which there was no detected free API was $40 \mathrm{wt} \%$ (Figure 6). When increasing the API content from 45 to $60 \mathrm{wt} \%, T_{\mathrm{S}}$ appears to reach a plateau, remaining at $145{ }^{\circ} \mathrm{C}$ despite the drug increase. Note that physical mixtures from 52.5 to 57.5 wt \% API (identified by single asterisk in Figure $6 \mathrm{~A}$ ) were only extruded at the dissolution end temperature $\left(150{ }^{\circ} \mathrm{C}\right)$. However, given the crystalline character of adjacent concentrations at 50 and $60 \mathrm{wt}$ $\%$ API at $140{ }^{\circ} \mathrm{C}$, it is reasonable to assume crystallinity of this intermediate concentration range at $140{ }^{\circ} \mathrm{C}$.

Apart from the impact of the temperature steps taken at each composition $\left(10^{\circ} \mathrm{C} / \mathrm{step}\right)$ the "plateau effect" is thought to be related to temperature-dependent structural changes of the polymer. It has been described that PVP-based polymers could assume helical conformation under specific circumstances which potentially could also occur during extrusion. ${ }^{44}$ This conformation would enable incorporation of additional drug molecules upon expansion, by reducing steric hindrance of API molecules already linked to the polymeric chain, and could explain the solubility increase despite the constant temperature. Further investigation is required to provide experimental support for this hypothesis, but this was out of the scope of the present work.

From 60 to $62.5 \mathrm{wt} \% \mathrm{API}, T_{\mathrm{S}}$ experiences an abrupt temperature increment. Above 65 wt \% API-load, as $T_{\text {EXTRUSION }}$ approaches the API melting point, the amorphous state of the drug is not a reflection of the polymer solubilization capacity. This is one of the limitations of this approach because it requires (i) miscible API-polymer systems where the API $T_{\mathrm{m}}>$ polymer $T_{\mathrm{g}}$ and (ii) processing temperatures below API $T_{\mathrm{m}}$ to enable detection of the excess crystalline API.

When comparing to PC-SAFT and $\mathrm{FH}$ predictions performed by Lehmkemper and co-workers, ${ }^{29}$ there are evident differences between predictions and experimental measurements performed in this study. PC-SAFT and $\mathrm{FH}$ predictions lack the plateau effect and solubility equilibrium is usually lower than the one determined by THz-Raman, especially at high polymer content. Even though the shape of the solubility curve and specific saturation temperatures differ, the magnitude of the values is of the same order. The work of Lehmkemper and co-workers shows that the maximum stable concentration of API in this polymer lies between 30 and 40\%, which is comparable to the critical concentration determined during this work using extrusion- $\mathrm{THz}$ (i.e., $40 \mathrm{wt} \%$ ). This suggests that this critical concentration could indicate the solid solution capacity of the polymer after HME processing and thus provides a concentration threshold that can differentiate stable/amorphous systems from metastable/unstable systems. This correlation will be elaborated upon in more detail later on.

Polymorphic Phase Identification. In order to assess eventual polymorphism occurring during extrusion, variabletemperature off-line $\mathrm{THz}$-Raman experiments were performed to obtain $\mathrm{THz}$ reference spectra of each polymorph. We used constrained crystallization under a microscope slide and a cover glass to kinetically trap polymorphs via the Ostwald rule of stages. Paracetamol has three known polymorphs under normal pressure conditions: monoclinic (form I, stable), orthorhombic (metastable, form II), and form III, the most metastable of all. ${ }^{45,46}$ Its recrystallization behavior from the 
amorphous glass is highly variable and dependent on both sample thermal history and the presentation method. ${ }^{47}$ Therefore, HSM, DSC, and variable-temperature XRPD experiments were performed as confirmatory techniques (results shown in Figures S2 and S3 in the Supporting Information section).

Collected THz-Raman spectra of polymorphs III, II, and I, as well as the amorphous form are shown in Figure 7. By

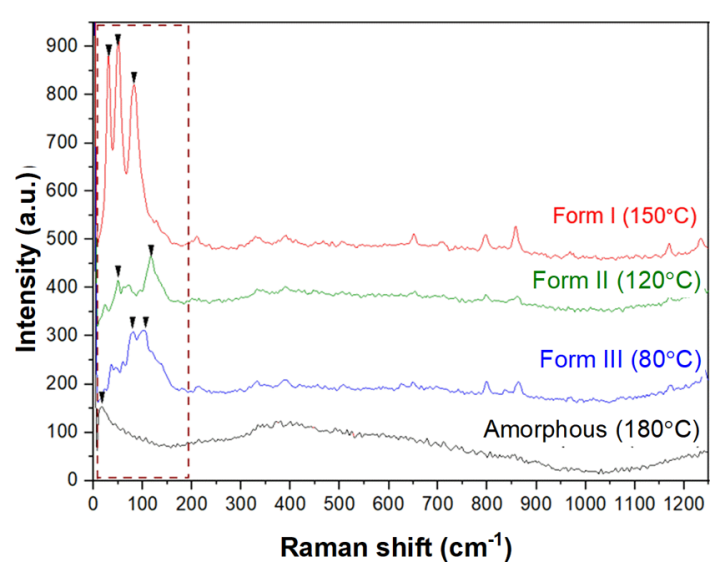

Figure 7. THZ-Raman spectra of amorphous PCM and crystalline forms III, II and I with respective recrystallisation temperatures from the amorphous glass. comparing the THz-Raman spectra obtained during HME with the reference spectra of each polymorph, only PCM form I was identified for both systems. There were no metastable crystalline forms during the API solubilization process nor recrystallization from the amorphous form during extrusion. Hence, measured solubility depicts PCM form I solubility in both matrices. However, recrystallization to different polymorphs could occur after HME for supersaturated systems.

Crystal Dissolution Behavior Observed by Hot-Stage Microscopy. It is interesting to note that at $T_{\mathrm{g}}$ of pure polymer, thermal diffusion and molecular mobility-essential to the mixing of the two chemical entities-were sufficient to fully dissolve the API up to $\mathrm{Cc}$ in both polymeric matrices during the short residence time in the extruder $(\sim 150 \mathrm{~s}$ for empty extruder conditions). Traditional DSC solubility protocols disregard solubility data near $T_{\mathrm{g}}$ because drug dissolution kinetics becomes much slower than the time scale of the measurement. ${ }^{12}$ However, the energy provided during extrusion via intensive mixing, shear stress, and temperature input was sufficient to overcome this barrier and dissolve the API. Thus, as an alternative means of understanding the thermodynamic driving force for crystal dissolution, HSM experiments were carried out to simulate the temperature conditions of the HME process by using isothermal steps of equal duration as the mean residence time within the extruder (empty barrel conditions).

Figure 8 shows the representative micrographs at the end of the isothermal steps in both polymeric matrices and sample

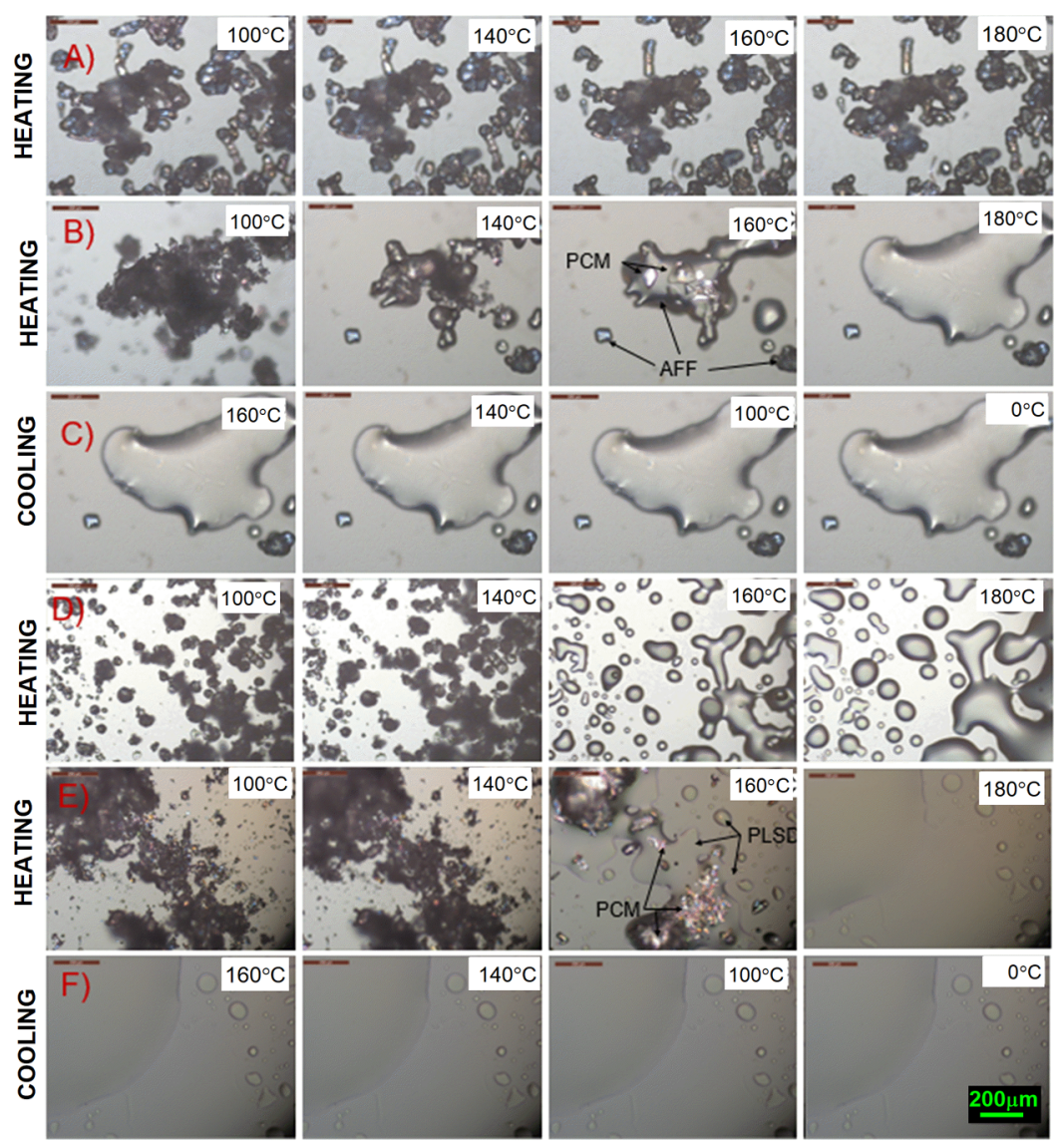

Figure 8. Hot stage microscopy images of (A) pure AFF; (B,C) PCM-AFF 20-80 wt \% during heating and cooling cycles, respectively; (D) pure PLSD upon heating cycle; (E,F) PCM-PLSD 30-70 wt \% during heating and cooling cycles, respectively. The scale bas is as indicated for all images. 
behavior during cooling cycles. Based on the birefringence properties, there is no observable API dissolution at the polymer $T_{\mathrm{g}}$, as both systems comprise just physical mixtures. Apart from heat transfer variations, without the HME-induced distributive and dispersive mixing, API dissolution is diffusion controlled (i.e., there is no mixing) and complete API dissolution occurs at higher temperatures, possibly due to kinetic constraints. However, upon complete dissolution, a single phase system is obtained, corroborating THz-Raman indication of miscibility. For both polymer systems during HSM analysis, there is no API recrystallization upon cooling, indicating that both polymers are capable of stabilizing the amorphous drug. The absence of recrystallization is also partially related to the intrinsic glass forming ability of the drug. ${ }^{48}$ There is also evidence of a marked API-induced plasticization effect. When in a single component system, Plasdone S630 (Figure 8D) experiences a drastic change in the viscoelastic properties with apparent liquefaction occurring at $160{ }^{\circ} \mathrm{C}\left(\sim 50{ }^{\circ} \mathrm{C}\right.$ above its $\left.T_{\mathrm{g}}\right)$, whereas pure Affinisol (Figure $8 \mathrm{~A})$ has higher viscosity and no evident liquefaction is observed up to $180^{\circ} \mathrm{C}$.

Predictive Value of the Critical Concentration. To validate our hypothesis with respect to the use of the critical concentration as a stability predictor, DSC and X-ray diffraction analysis were performed to assess the physical state of the extrudates after extrusion. For this purpose, only samples processed at the dissolution end temperature (lowest temperature required for complete API amorphisation) were considered for each composition.

DSC thermograms of PCM, AFF, and PCM-AFF extrudates are displayed in Figure 9A. Up to the critical concentration $(\mathrm{Cc}=20 \mathrm{wt} \%)$, there is no evidence of endothermic events because of melting of the crystalline material. For drug loadings $>20 \mathrm{wt} \%$, there is an exotherm at $140-150{ }^{\circ} \mathrm{C}$ depicting partial recrystallization to form II, and two melting endotherms at $\sim 155$ and $170{ }^{\circ} \mathrm{C}$, ascribed to melting of forms II and I, respectively.

XRPD analysis (Figure 9B) confirmed the lack of crystallinity up to $20 \mathrm{wt} \%$ drug loading, as indicated by the halo pattern characteristic of amorphous materials. In contrast, Bragg peaks corresponding to PCM form I were found for all concentrations above $\mathrm{Cc}$. An additional diffraction peak with maxima at $\sim 32^{\circ}(2 \theta)$ was observed in the diffractograms of pure Affinisol and all low API-loading extrudates. This peak is ascribed to $\mathrm{NaCl}$ that is used as a manufacturing additive for Affinisol $15 \mathrm{LV}$ up to $5 \mathrm{wt} \%$. It should be noted that $\mathrm{NaCl}$ was not spectrally active in the THz-Raman region and therefore had no contribution to crystallinity detected during extrusion.

The same recrystallization trend is observed for Plasdonebased extrudates. Up to the critical concentration $(\mathrm{Cc}=40 \mathrm{wt}$ $\%)$, there is a single-phase amorphous dispersion with no melting endotherms (Figure 10A). At 42.5, 45 and $50 \mathrm{wt} \%$, the small melting endotherm at $169{ }^{\circ} \mathrm{C}$, denotes melting of PCM form I. At higher drug loadings, there are two endotherms at ca. $160{ }^{\circ} \mathrm{C}$ (melting of form II) and $169{ }^{\circ} \mathrm{C}$ (melting of form I). X-ray diffraction analysis is depicted in Figure 10B. It corroborated the amorphous character of the extrudates up to the Cc. For formulations $\geq 42.5 \mathrm{wt} \%$, crystalline peaks corresponding to form I were found and as expected, their intensity increased with increasing the API mass fraction. Given its absence in the XRPD patterns, form II is thought to be thermally induced by the DSC heating scan for both polymers.
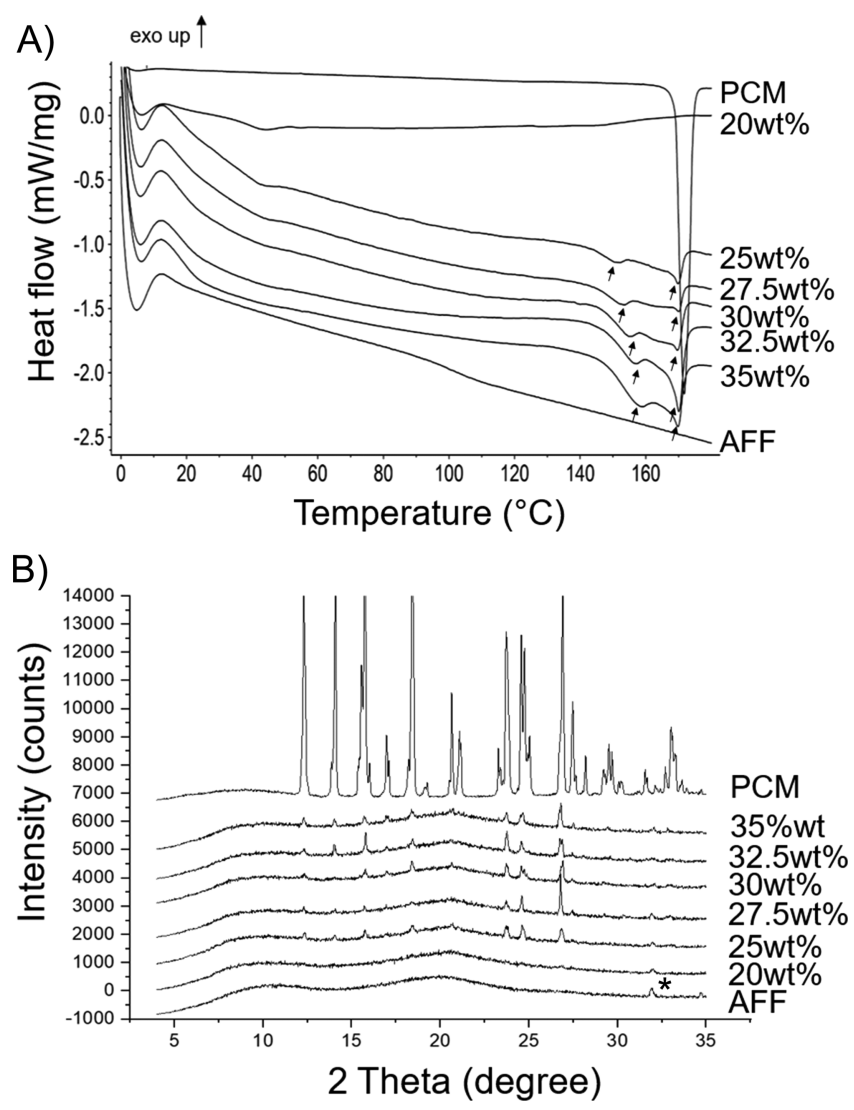

Figure 9. (A) DSC thermographs and (B) XRPD diffractograms of PCM, AFF and PCM-AFF extrudates with different API contents.

Appearance of crystalline API following cooling of the extrudates suggests that the solubility limit has been exceeded. This was evident for all API-polymer extrudates with drugloadings above Cc (i.e., $>20 \mathrm{wt} \%$ for PCM-AFF and $>40 \mathrm{wt}$ $\%$ for PCM-PLSD). This offers compelling evidence that (i) THz-Raman identification of the saturated solution temperature is valid and (ii) that the critical concentration has the ability to differentiate ASD formulations that are truly unstable/metastable and those which are more likely to be stable at the point of use. Based on the correlation between Cc and DSC and XRPD amorphicity, the maximum solubility of paracetamol at temperatures encountered post HME in Affinisol and Plasdone are $\leq 20$ and $\leq 40$ wt \% respectively. Thus, Cc appears to provide a maximum drug-loading threshold that can be used to infer ASD physical stability at the point of developing the manufacturing process. This enables early identification of recrystallization tendencies within an ASD and allows identification of the maximum API load that can be molecularly dispersed in the polymer during extrusion and remain amorphous at the point of use.

The THz-Raman method herein developed has allowed us to obtain an insight into the likely equilibrium solubility range for these particular systems. Care was taken to allow extrusion to reach the steady state at each experimental condition and THz-Raman data were only considered when steady state conditions were satisfied. This allied with the length of the 16 $\mathrm{mm}$ extrusion unit (HME length $(L) /$ diameter $(D)=40)$ and the intensive mixing provided offers sufficient confidence to assume true equilibrium was reached and that observed solubility data are not constrained by kinetic limitations. 


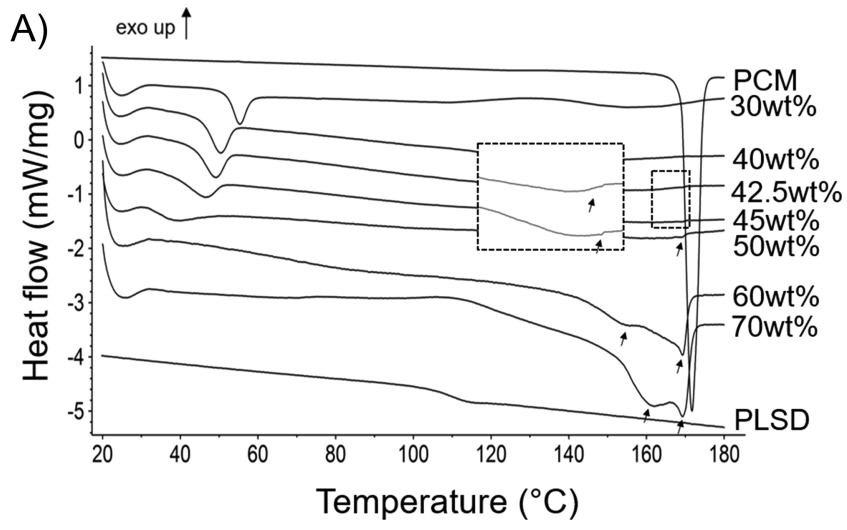

the polymer during extrusion and remain in the amorphous state at storage conditions after HME. DSC and XRPD analysis supported this inference and showed that this critical concentration could be used as a stability predictor.

Overall, solubility data generated by this approach provide a more accurate reflection of the likely solubility equilibrium for optimum HME processing at temperatures below the API $T_{m}$ and a reliable alternative solubility measurement for determining stable ASDs. This approach also offers an important in-line process control tool for process optimization and $\mathrm{QbD}$ implementation in the manufacture of HME-based ASDs.

\section{ASSOCIATED CONTENT}

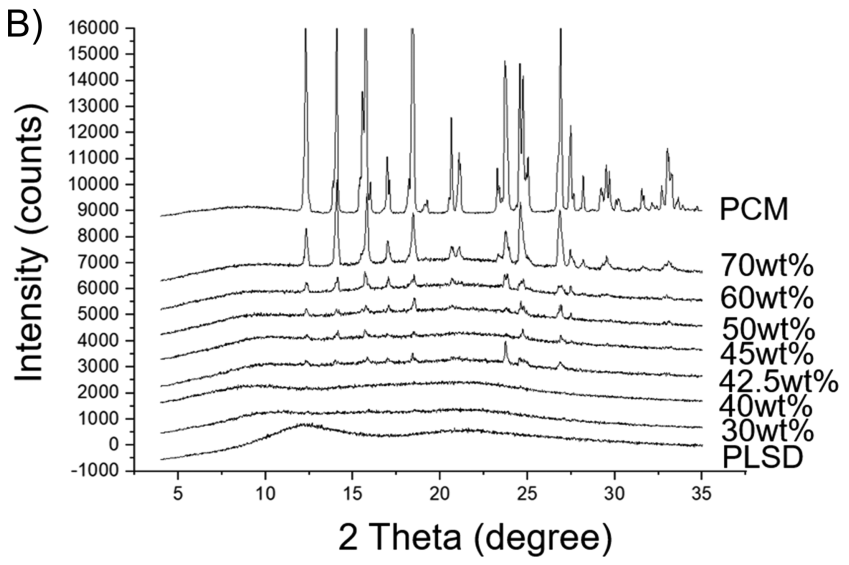

\section{S Supporting Information}

The Supporting Information is available free of charge on the ACS Publications website at DOI: 10.1021/acs.molpharmaceut.9b00703.

THz-Raman spectra at the critical API concentration and paracetamol recrystallization behavior from the amorphous glass: VT-XRPD and DSC studies and HSM analysis (PDF)

\section{AUTHOR INFORMATION}

\section{Corresponding Author}

*E-mail: j.robertson@strath.ac.uk. Phone: +44-141-444-7130.

\section{ORCID $\odot$}

Alastair J. Florence: 0000-0002-9706-8364

Figure 10. (A) DSC thermographs and (B) XRPD diffractograms of PCM, PLSD and PCM-PLSD extrudates with different API contents.

Furthermore, by enabling in-line drug-polymer solubility determination, this method also provides a valuable process analytical technology (PAT) tool for process optimization during the development of new ASDs systems by HME. It has also the potential to correlate product critical quality attributes, such as residual crystallinity, to HME critical process parameters such as residence time, screw speed, feed rate, screw configuration, and processing temperature, as promoted by the International Conference on Harmonization (ICH) Q8 (R2) and quality by design (QbD) approaches advised by regulatory authorities, namely Food and Drug Administration (FDA) and European Medicines Agency (EMA). Apart from the processing temperature, these parameters were not allowed to vary in this first exploratory study but will be considered in future experiments.

\section{CONCLUSIONS}

The objective of this study was to explore a new method to enable solubility determination of crystalline API in polymeric matrices directly during HME. For the first time, lowfrequency terahertz-Raman spectroscopy was coupled with HME to monitor the drug structural phase transitions as a means of providing real-time solubility. As a proof of concept, the solubility of Paracetamol in Affinisol $15 \mathrm{LV}$ and Plasdone S630 was determined. Successful identification of the saturated solution temperature enabled construction of solubility phase diagrams for the binary systems. From the phase diagrams generated in this manner, a critical API concentration was identified, $20 \mathrm{wt} \%$ for Affinisol $15 \mathrm{LV}$ and $40 \mathrm{wt} \%$ for Plasdone S630. This critical concentration was found to reveal the maximum API load that can be molecularly dispersed in

Gavin W. Halbert: 0000-0001-8553-3647

John Robertson: 0000-0002-2191-1319

\section{Notes}

The authors declare no competing financial interest.

\section{ACKNOWLEDGMENTS}

The authors would like to thank EPSRC, the Doctoral Training Centre in Continuous Manufacturing and Crystallisation, CMAC (grant ref: EP/P006965/1) and RE-configuring MEDIcines End-to-end Supply (REMEDIES) project for funding. This work was carried out in the CMAC National Facility supported by UKRPIF (UK Research Partnership Fund) award from the Higher Education Funding Council for England (HEFCE, grant EFHH13054). The authors would also like to acknowledge Perceptive Engineering Ltd. for PharmaMV assistance, as well as DowDuPont and Ashland for Affinisol 15LV and Plasdone S630 kind donations, respectively. G.W.H. was funded by Cancer Research UK (gran ref: C149/ A20740).

\section{ABBREVIATIONS}

BCS, Biopharmaceutical classification system; ASD, amorphous solid dispersion; API, active pharmaceutical ingredient; DSC, differential scanning calorimetry; HME, hot melt extrusion; F-H, Flory-Huggins; PC-SAFT, perturbed-chain statistical associating theory; $\mathrm{THz}$, terahertz; PCM, paracetamol; AFF, Affinisol 15LV; PLSD, Plasdone S630; HSM, hot-stage microscopy; XRPD, X-ray powder diffraction; $T_{\mathrm{S}}$, saturated solution temperature; $T_{\text {EXTRUSION }}$, extrusion temperature; Cc, critical concentration; $T_{g}$, glass transition temperature; $\mathrm{QbD}$, quality by design; PAT, process analytical technology; FDA, Food and Drug Administration; EMA, European Medicines Agency 


\section{REFERENCES}

(1) Kumar, S. D.; Bihari, G. V.; Suresh, P.; Dinesh, S. Solubility Improvement Using Solid Dispersion; Strategy, Mechanism and Characterization : Responsiveness and Prospect Way Outs. Int. Res. J. Pharm. 2011, 2, 55-60.

(2) Jain, S.; Patel, N.; Lin, S. Solubility and dissolution enhancement strategies: Current understanding and recent trends. Drug Dev. Ind. Pharm. 2015, 41, 875-887.

(3) Benet, L. Z. Predicting drug disposition via application of a biopharmaceutics drug disposition classification system. Basic Clin. Pharmacol. Toxicol. 2010, 106, 162-167.

(4) Winslow, C. J.; et al. Cellulose-based amorphous solid dispersions enhance rifapentine delivery characteristics in vitro. Carbohydr. Polym. 2018, 182, 149-158.

(5) Martinez-Marcos, L.; Lamprou, D. A.; McBurney, R. T.; Halbert, G. W. A novel hot-melt extrusion formulation of albendazole for increasing dissolution properties. Int. J. Pharm. 2016, 499, 175-185.

(6) Ohyagi, N.; et al. Synergetic Role of Hypromellose and Methacrylic Acid Copolymer in the Dissolution Improvement of Amorphous Solid Dispersions. J. Pharm. Sci. 2017, 106, 1042-1050.

(7) Hanada, M.; Jermain, S. V.; Williams, R. O. Enhanced Dissolution of a Porous Carrier-Containing Ternary Amorphous Solid Dispersion System Prepared by a Hot Melt Method. J. Pharm. Sci. 2018, 107, 362-371.

(8) Vasconcelos, T.; Sarmento, B.; Costa, P. Solid dispersions as strategy to improve oral bioavailability of poor water soluble drugs. Drug Discovery Today 2007, 12, 1068-1075.

(9) Zografi, G.; Newman, A. Interrelationships Between Structure and the Properties of Amorphous Solids of Pharmaceutical Interest. J. Pharm. Sci. 2017, 106, 5-27.

(10) De Araujo, G. L. B.; Benmore, C. J.; Byrn, S. R. Local Structure of Ion Pair Interaction in Lapatinib Amorphous Dispersions characterized by Synchrotron X-Ray diffraction and Pair Distribution Function Analysis. Sci. Rep. 2017, 7, 46367.

(11) Sekiguchi, K.; Obi, N. Studies on Absorption of Eutectic Mixture. I. A Comparison of the Behavior of Eutectic Mixture of Sulfathiazole and that of Ordinary Sulfathiazole in Man. Chem. Pharm. Bull. 1961, 9, 866-872.

(12) Qian, F.; Huang, J.; Hussain, M. A. Drug-Polymer Solubility and Miscibility: Stability Consideration and Practical Challenges in Amorphous Solid Dispersion Development. J. Pharm. Sci. 2010, 99, 2941-2947.

(13) Lin, X.; et al. Physical Stability of Amorphous Solid Dispersions: a Physicochemical Perspective with Thermodynamic, Kinetic and Environmental Aspects. Pharm. Res. 2018, 35, 125.

(14) Amharar, Y.; Curtin, V.; Gallagher, K. H.; Healy, A. M. Solubility of crystalline organic compounds in high and low molecular weight amorphous matrices above and below the glass transition by zero enthalpy extrapolation. Int. J. Pharm. 2014, 472, 241-247.

(15) Lehmkemper, K.; Kyeremateng, S. O.; Bartels, M.; Degenhardt, M.; Sadowski, G. Physical stability of API/polymer-blend amorphous solid dispersions. Eur. J. Pharm. Biopharm. 2018, 124, 147-157.

(16) Yang, Z.; Nollenberger, K.; Albers, J.; Qi, S. Molecular implications of drug-polymer solubility in understanding the destabilization of solid dispersions by milling. Mol. Pharm. 2014, 11, 2453-2465.

(17) Luebbert, C.; Klanke, C.; Sadowski, G. Investigating phase separation in amorphous solid dispersions via Raman mapping. Int. J. Pharm. 2018, 535, 245-252.

(18) Theil, F.; et al. Frozen in Time: Kinetically Stabilized Amorphous Solid Dispersions of Nifedipine Stable after a Quarter Century of Storage. Mol. Pharm. 2016, 14, 183-192.

(19) Tao, J.; Sun, Y.; Zhang, G. G. Z.; Yu, L. Solubility of SmallMolecule Crystals in Polymers: D-Mannitol in PVP, Indomethacin in PVP/VA, and Nifedipine in PVP/VA. Pharm. Res. 2008, 26, 855864.

(20) Sun, Y.; Tao, J.; Zhang, G. G. Z.; Yu, L. Solubilities of crystalline drugs in polymers: An improved analytical method and comparison of solubilities of indomethacin and nifedipine in PVP, PVP/VA, and PVAc. J. Pharm. Sci. 2010, 99, 4023-4031.

(21) Mahieu, A.; Willart, J.-F.; Dudognon, E.; Danède, F.; Descamps, M. A New Protocol To Determine the Solubility of Drugs into Polymer Matrixes. Mol. Pharmaceutics 2013, 10, 560.

(22) Rask, M. B.; Knopp, M. M.; Olesen, N. E.; Holm, R.; Rades, T. Comparison of two DSC-based methods to predict drug-polymer solubility. Int. J. Pharm. 2018, 540, 98-105.

(23) Tian, Y.; et al. Construction of drug-polymer thermodynamic phase diagrams using flory-huggins interaction theory: Identifying the relevance of temperature and drug weight fraction to phase separation within solid dispersions. Mol. Pharm. 2013, 10, 236-248.

(24) Zhao, Y.; Inbar, P.; Chokshi, H. P.; Malick, A. W.; Choi, D. S. Prediction of the thermal phase diagram of amorphous solid dispersions by flory-huggins theory. J. Pharm. Sci. 2011, 100, 31963207.

(25) Wlodarski, K.; Sawicki, W.; Kozyra, A.; Tajber, L. Physical stability of solid dispersions with respect to thermodynamic solubility of tadalafil in PVP-VA. Eur. J. Pharm. Biopharm. 2015, 96, 237-246.

(26) Kyeremateng, S. O.; Pudlas, M.; Woehrle, G. H. A fast and reliable empirical approach for estimating solubility of crystalline drugs in polymers for hot melt extrusion formulations. J. Pharm. Sci. 2014, 103, 2847-2858.

(27) Paus, R.; Ji, Y.; Vahle, L.; Sadowski, G. Predicting the Solubility Advantage of Amorphous Pharmaceuticals: A Novel Thermodynamic Approach. Mol. Pharm. 2015, 12, 2823-2833.

(28) Prudic, A.; Ji, Y.; Luebbert, C.; Sadowski, G. Influence of humidity on the phase behavior of API/polymer formulations. Eur. J. Pharm. Biopharm. 2015, 94, 352-362.

(29) Lehmkemper, K.; Kyeremateng, S. O.; Heinzerling, O.; Degenhardt, M.; Sadowski, G. Long-Term Physical Stability of PVP- and PVPVA-Amorphous Solid Dispersions. Mol. Pharm. 2016, 14, 157-171.

(30) Janssens, S.; et al. Influence of Preparation Methods on Solid State Supersaturation of Amorphous Solid Dispersions: A Case Study with Itraconazole and Eudragit E100. Pharm. Res. 2010, 27, 775-785.

(31) Caron, V.; Tajber, L.; Corrigan, O. I.; Healy, A. M. A Comparison of Spray Drying and Milling in the Production of Amorphous Dispersions of Sulfathiazole/Polyvinylpyrrolidone and Sulfadimidine/Polyvinylpyrrolidone. Mol. Pharm. 2011, 8, 532-542.

(32) Yang, Z.; et al. The effect of processing on the surface physical stability of amorphous solid dispersions. Eur. J. Pharm. Biopharm. 2014, 88, 897-908.

(33) Nanubolu, J. B.; Burley, J. C. Investigating the recrystallization behavior of amorphous paracetamol by variable temperature Raman studies and surface raman mapping. Mol. Pharm. 2012, 9, 1544-1558. (34) Al-Dulaimi, S.; Aina, A.; Burley, J. Rapid polymorph screening on milligram quantities of pharmaceutical material using phononmode Raman spectroscopy. CrystEngComm 2010, 12, 1038-1040.

(35) Mori, S. K. T.; Shibata, T.; Kobayashi, Y. Broadband Terahertz Time-Domain and Low-Frequency Raman Spectroscopy of Crystalline and Glassy Pharmaceuticals. Pharm. Anal. Acta 2015, 6, 401.

(36) Singh, R.; George, D. K.; Benedict, J. B.; Korter, T. M.; Markelz, A. G. Improved Mode Assignment for Molecular Crystals Through Anisotropic Terahertz Spectroscopy. J. Phys. Chem. A 2012, 116, 10359-10364.

(37) Larkin, P. J.; Wasylyk, J.; Raglione, M. Application of Low- and Mid-Frequency Raman Spectroscopy to Characterize the AmorphousCrystalline Transformation of Indomethacin. Appl. Spectrosc. 2015, $69,1217-1228$.

(38) Ma, X.; et al. Influence of mechanical and thermal energy on nifedipine amorphous solid dispersions prepared by hot melt extrusion: Preparation and physical stability. Int. J. Pharm. 2019, 561, 324-334.

(39) Evans, R. C.; Bochmann, E. S.; Kyeremateng, S. O.; Gryczke, A.; Wagner, K. G. Holistic QbD approach for hot-melt extrusion process design space evaluation: Linking materials science, experimentation and process modeling. Eur. J. Pharm. Biopharm. 2019, 141, 149-160. 
(40) Marsac, P. J.; Shamblin, S. L.; Taylor, L. S. Theoretical and practical approaches for prediction of drug-polymer miscibility and solubility. Pharm. Res. 2006, 23, 2417-2426.

(41) Knopp, M. M.; et al. Comparative Study of Different Methods for the Prediction of Drug-Polymer Solubility. Mol. Pharm. 2015, 12, 3408-3419.

(42) Prasad, E.; et al. Development of a hot-melt extrusion (HME) process to produce drug loaded Affinisol ${ }^{\mathrm{TM}} 15 \mathrm{LV}$ filaments for fused filament fabrication (FFF) 3D printing. Addit. Manuf. 2019, 29, 100776.

(43) Moseson, D. E.; Taylor, L. S. The application of temperaturecomposition phase diagrams for hot melt extrusion processing of amorphous solid dispersions to prevent residual crystallinity. Int. J. Pharm. 2018, 553, 454-466.

(44) Du, Q.; Harding, D. R.; Yang, H. Helical peanut-shaped poly(vinyl pyrrolidone) ribbons generated by electrospinning. Polymer 2013, 54, 6752-6759.

(45) Perrin, M.-A.; Neumann, M. A.; Elmaleh, H.; Zaske, L. Crystal structure determination of the elusive paracetamol Form III. Chem. Commun. 2009, 0, 3181.

(46) Shekunov, B. Y.; Aulton, M. E.; Adama-Acquah, R. W.; Grant', D. J. W. Effect of temperature on crystal growth and crystal properties of paracetamol. J. Chem. Soc., Faraday Trans. 1996, 92, 439.

(47) Qi, S.; Avalle, P.; Saklatvala, R.; Craig, D. Q. M. An investigation into the effects of thermal history on the crystallisation behaviour of amorphous paracetamol. Eur. J. Pharm. Biopharm. 2008, 69, 364-371.

(48) Blaabjerg, L. I.; Lindenberg, E.; Löbmann, K.; Grohganz, H.; Rades, T. Is there a correlation between the glass forming ability of a drug and its supersaturation propensity? Int. J. Pharm. 2018, 538, 243-249. 